\title{
Globalização contemporânea e novas tecnologias: uma leitura arrighiana
}

\author{
Livio Andrade Wanderley ${ }^{1}$
}

Resumo: O propósito do artigo foi o de abordar os temas integração mundial e globalização atual e em fases passadas. Esse intento foi cumprido através de uma interpretação de efeitos dos padrões tecnológicos das três revoluções industriais, e na forma de expansão espacial do capital em escala mundial. A reflexão à luz do estudo de Giovanni Arrighi baseou-se na leitura sobre o seu modelo de "ciclos sistêmicos de acumulação" que envolve a mundialização do capital, a recorrência histórica, e as hegemonias de Estados nações. Com o fim de mostrar que a configuração da atual economia globalizada difere de forma significativa em relação à integração econômica mundial de períodos históricos passados, são abordados aspectos relacionados com as acumulações, produtiva e financeira, aos padrões de competitividade e diluição de fronteiras regionais, a integração mundial, e a hipótese de um 5 ํ Ciclo Sistêmico de Acumulação.

Palavras-chave: Tecnologia; Capitalismo; Globalização. 


\title{
Contemporary globalization and new technologies: Arrighi's Study
}

\begin{abstract}
The purpose of the article was to research the issues integration and globalization today and in past phases. This purpose was fulfilled through an interpretation of the effects of technological standards of the three industrial revolutions, and in the form of spatial expansion of capital on a global scale. The reflection in the light of Giovanni Arrighi's study was based on reading about his model of "systemic cycles of accumulation" involves the globalization of capital, the historical recurrence, and the hegemony of nation states. In order to show that the configuration of today's global economy differs significantly in relation to global economic integration of historical periods in the past, we address aspects related to the accumulation, production and financial standards of competition and dilution of the same region, the global integration, and the hypothesis of a $5^{\circ}$ cycle system of accumulation.
\end{abstract}

Keywords: Technology; Capitalism; Globalization.

\section{Introdução}

Nas últimas quatro décadas o tema "globalização" tem sido tratado como um fenômeno novo, abrangente e emergente para alguns e para outros como um fato já conhecido historicamente. No que pese o processo histórico da reprodução econômica não poder ser rigorosamente datado, este artigo considera que a partir dos anos 70 o mundo tem convivido com mudanças estruturais nas relações socioeconômicas, caracterizando-se esse período como a fase de uma economia globalizada que se distingue das formas de integração mundial passada. Diante desse posicionamento, pretende-se mostrar a diferença da atual estrutura sistêmica em escala mundial, ancorada em uma tecnologia à base da "microeletrônica e automação" que sustenta a terceira revolução industrial; com as estruturas historicamente definidas, segundo os padrões tecnológicos baseados na "mecânica" e na "eletricidade e eletrônica" que respaldaram a primeira e a segunda revolução industrial, respectivamente.

Com relação ao modelo do Ciclo Sistêmico de Acumulação (CSA) desenvolvido por Giovanni Arrighi em seu livro "O longo século $X X$ ”, demonstra-se que tem havido uma recorrência histórica da acumulação financeira como forma de reprodução, em escala mundial, da economia e do sistema de he- 
gemonias de estados nacionais. A compreensão da leitura arrighiana envolve uma dimensão analítica que tem afinidade com os estudos do sistema mundo de Wallerstein ${ }^{2}$, e com os estudos de Braudel sobre a estrutura da economia em três andares - vida material, mercado e antimercado - e, sobre a sua visão do capital como parceiro dependente e que se confunde com o Estado, caracterizando-se no estágio do antimercado. ${ }^{3}$ Dessa forma, a reflexão desse trabalho aborda aspectos sobre a espacialidade mundial, reprodução do capital e hegemonias de Estados nações.

Considerando que o uso de um padrão e estágio de tecnologia serve como uma base explicativa para se distinguir as estruturas sistêmica mundiais, atual e passadas, o artigo, através das indagações descritas abaixo, tem o propósito de refletir sobre alguns aspectos que são influenciados pelas novas tecnologias, por exemplo: da rigidez da acumulação produtiva, dos padrões de competitividade no mercado global, das novas formas de integração econômica mundial, das modalidades e movimento do capital financeiro, e da hipótese de se apresentar ou não um novo ciclo sistêmico de acumulação. Dessa forma, as questões a seguir, propiciam discernir sobre as diferenças do que se poderia denominar de globalização do passado ${ }^{4}$ e contemporânea.

- As novas tecnologias tornaram os processos de acumulação e gestão da produção material flexível?

- Os atuais padrões de competitividade resultam na busca de rendas tecnológicas e diluição de fronteiras geográficas?

- A globalização atual apresenta características de integração regional fragmentada e em blocos regionais de Estados nações?

- A acumulação do capital financeiro se tornou ainda mais autônoma através da diversificação de seus produtos e da sua mobilidade internacional?

\footnotetext{
2 Este autor considera o capitalismo, desde o início, como pertencente à chamada economia-mundo e não de Estados nações, e que é um erro afirmar que o capitalismo se tornou mundial apenas no século XX.

3 É comum se considerar o sistema capitalista e a economia de mercado como algo similar, bem como o Estado como um agente de oposição a esse sistema. Não obstante, com uma posição contrária, Braudel "encara a emergência e a expansão do capitalismo como absolutamente dependente do poder estatal, constituindo-se esse sistema na antítese da economia e mercado." (Braudel apud Arrighi, 1996: 10)

4 Hirst, \& Thompson (1998), críticos do tema globalização, alegam que se ela existe hoje não se trata de um fenômeno novo.
} 
- É possível se reproduzir um novo e $5^{\circ} \mathrm{CSA}$ ?

Colocados os propósitos do artigo, a sua composição requer um esclarecimento sobre alguns aspectos conceituais que fundamenta o estudo de Arrighi, a ser tratado na seção 2. Na seção 3 é apresentado o esquema de reprodução histórica dos CSAs. Na seção 4, contextualizam-se as formas de integração mundial passada e seus padrões tecnológicos. Na seção 5, fazem-se uma reflexão sobre o atual ciclo sistêmico associado com a natureza de sua tecnologia que sustenta o conceito da globalização contemporânea. Na seção 6, apresentam-se algumas considerações conclusivas das reflexões feitas no artigo.

\section{Conceitos básicos}

A exposição de conceitos de Arrighi e do seu modelo dos ciclos sistêmicos possibilita discernir sobre o que vem a ser uma leitura histórica da reprodução econômica e das hegemonias de Estados nacionais, com a atual realidade, que sendo parte do $4^{\circ} \mathrm{CSA}$, opera com um novo tipo de tecnologia substanciado pelos chips e que ancora a terceira revolução industrial.

A reflexão histórica feita por Arrighi contextualiza uma análise a partir da formação do sistema de Estados nações da era moderna, concomitantemente a criação do sistema capitalista em escala mundial. Apesar da tese levantada por Lênin (1979) e Hilferding (1985) sobre o anúncio de que o capital financeiro era o último e o mais avançado e especial estágio do capitalismo mundial em sua fase imperialista, Arrighi incorpora o esquema interpretativo de Fernand Braudel como base para sua obra. Por este esquema, o capitalismo financeiro não é uma etapa especial e nem um fenômeno recente, é sim, um evento recorrente que vem marcando o sistema capitalista desde a sua fase mais rudimentar.

Na formulação do seu modelo, Arrighi adota a concepção de Braudel sobre o capitalismo, a qual se apoiando no esquema (DMD') de Marx, enfatiza a capacidade multiplicativa da moeda, seja qual for o meio que possibilita a sua reprodução, como fica claro nesta citação:

"aquilo que, na definição braudeliana do capitalismo, faz com que um agente ou uma camada social seja capitalista não é sua predisposição a investir num dado produto (p. ex., a força de trabalho) ou esfera de atividade (p. ex., a indústria). Um agente é capitalista em virtude do fato de seu dinheiro ser sistemática e persistentemente dotado da "capacidade de multiplicar-se" (expressão de Marx), seja qual for a natureza das mercadorias e atividades 
específicas que constituem, num dado momento, o meio contingente. (Arrighi, 1996; 8). ${ }^{5}$

As características essenciais do processo histórico da reprodução e expansão do capitalismo foram a "flexibilidade e o ecletismo do capital", e não as formas rígidas e material assumidas por ele em diferentes lugares e épocas.

Muitos autores encaram a revolução industrial do século XIX como o marco que deu ao capitalismo uma verdadeira identidade. No entanto, Braudel ressalta a predominância ou hegemonia de uma nação sob a forma capitalista desde a Itália do século XIII (Arrighi, 1996). Para tal, Arrighi reafirma a fórmula geral do capital de Marx, DMD', em que:

"O capital-dinheiro (D) significa liquidez, flexibilidade e liberdade de escolha. O capital-mercadoria (M) é o capital investido numa dada combinação de insumo-produto, visando ao lucro; portanto, significa concretude, rigidez e um estreitamento ou fechamento das opções. D' representa a ampliação da liquidez, da flexibilidade e da liberdade das opções." (Arrghi, 1996; 5).

Dessa forma, a interpretação da fórmula geral do capital de Marx pode ser vista como investimentos de capitalistas individuais, como padrão do sistema capitalista global, e como alternância de fases de expansão material (DM) e comercial (MD'), com fases de expansão financeira (DD'). Baseando-se nessa lógica, o capitalista não tem apenas o objetivo da simples produção de mercadorias, e sim da multiplicação do capital, pois o investimento na produção material e no comércio tende a retornar a sua forma monetária e a se acumular mais diretamente e com mais rapidez, segundo a forma (DD') da acumulação financeira.

É com base nesse cenário conceitual e histórico que se pretende argumentar, com base no atual padrão de tecnologia, as diferenças entre a globalização passada - ancorada nas formas tradicionais de comércio internacional e de fluxos de capitais, sob a liderança de um Estado nacional -, e a globalização contemporânea - calcada em uma tecnologia que provoca a fragmentação em escala mundial da produção e do comércio, enfraquecendo a existência de um Estado nação que seja hegemônico.

\section{Ciclos sistêmiscos de acumulação}

O modelo CSA de Arrighi traz uma leitura composta de quatro ciclos de reprodução econômica e de hegemonias de Estados nações, proporcionando-se a expansão do capitalismo e a integração da economia internacional.

5 A tese da capacidade multiplicativa do dinheiro de forma abrangente transcende a referência da reprodução do capital fundada apenas nas formas materiais de produção industrial e nas relações de assalariamento, como se apresenta o modelo de Marx DMD'. 
Esses ciclos se iniciam nos estudos de Arrighi com a hegemonia de Gênova entre as Cidades Estados Italianas (Florença, Veneza, Gênova e Milão), seguidas das hegemonias da Holanda, da Inglaterra e dos Estados Unidos. Dado a existência de estados territorialistas calcados nas conquistas de terras e de comunidades configurados no modelo (TDT') descrito por Arrighi, em que o dinheiro (D) é meio e o território (T) é o fim dos estados hegemônicos, constata-se que Estados nações, em geral, ora combinavam os propósitos territorialistas com os da acumulação do capital através do modelo (DTD') em que o território é meio e o dinheiro é fim, ora priorizavam apenas esta última finalidade. A dinâmica dos ciclos sistêmicos tem ocorrido através dos processos de acumulação e saturação do capital rígido (DM) e o consequente crescimento da acumulação e movimentação espacial do capital flexível (DD'), que correspondem às formas de atividades materiais, e financeiras, respectivamente.

A Figura 1, a seguir, detalha os CSAs traduzidos nos longos séculos XVI, XVII, XIX e XX, em que se faz uma leitura na escala horizontal (abscissa) desses séculos e das recorrências de períodos de expansões materiais (EP) e de expansões financeiras (EF). Os longos séculos se iniciam em cada uma das crises sinalizadoras (s) de um estado hegemônico em vigor e finaliza em cada uma das crises terminais ( $\mathrm{t}$ ) do novo estado hegemônico. As expansões materiais (EP) de cada estado hegemônico ocorrem entre as crises sinalizadoras dos estados hegemônicos anteriores e em andamento. As expansões financeiras (EF) que caracterizam as transições de hegemonias acontecem nos intervalos entre as crises sinalizadoras e terminais de cada estado hegemônico. A leitura na escala vertical (ordenada) registram os movimentos ao longo dos ciclos, um processo de expansão mundial da economia e os incrementos nos padrões de tecnologia e inovação industrial.

As formas de integração econômica mundial são monitoradas pelas oportunidades em que a evolução técnica tem contribuído para a construção de um sistema mundo, tal que os ganhos da integração se deram, em uma primeira fase através da predominância das rendas do comércio internacional e, em uma segunda fase através de rendas de investimentos diretos externos. Atualmente os ganhos da globalização estão associados ao conceito de rendas tecnológicas. ${ }^{6} \mathrm{Na}$ Figura 1, apreendem-se no decorrer dos ciclos sistêmicos os processos de inovações e rupturas tecnológicas, e de reprodução e expansão espacial do capital. 


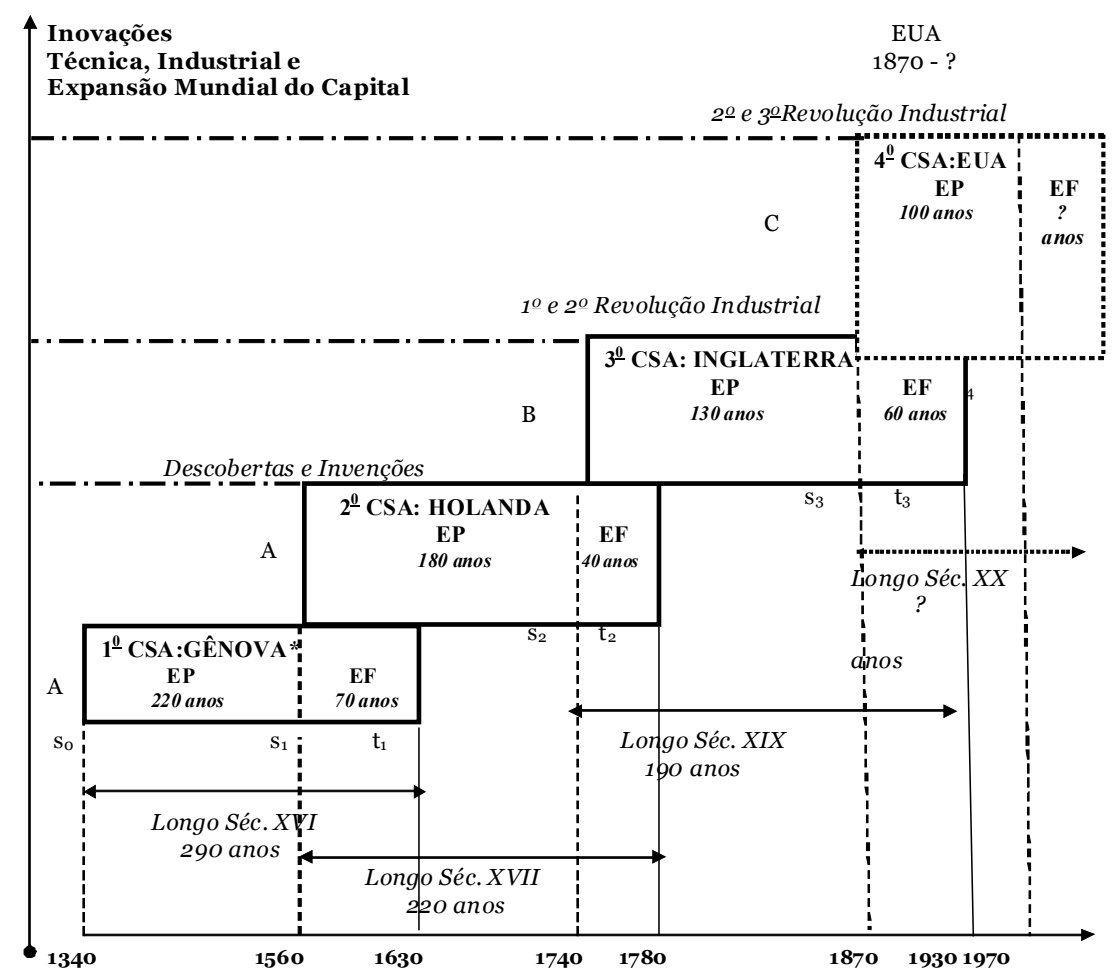

* Mais relevante das Cidades Estado Italianas (CEI): Gênova, Veneza, Florença e Milão.

NOTA: 1) Os principais custos dos CSAs foram: $A$ = Proteção, $B=$ Produção, $C$ = Transação. 2) Os períodos cronológicos se iniciaram e terminaram em torno dos anos acima.

Fonte: Adaptado de Arrighi (1996: 219).

A evolução histórica dos longos séculos se contrai na medida em que evoluem os padrões de tecnologia, de organização empresarial e social, bem como as instituições de cada época, pois se observa na Figura 1 que tem havido uma redução de anos de cada CSA, o que pode ser percebido através das leituras seculares, ou seja, 290, 220 e 190 anos para os respectivos longos séculos XVI, XVII e XIX. ${ }^{7}$ Da mesma forma os CSAs medidos pelas expansões materiais (EP) também se contraem, dado que duraram 220, 180, 130 e 100 anos para

7 O longo século XX não tem ainda uma definição sobre a sua crise terminal $t_{4}$. Não estou considerando o recente estudo de Arrighi (2008) que em seu epílogo enfatiza a precipitação da "crise terminal" da hegemonia americana e da possibilidade, ainda não assegurada, de uma nova sociedade baseada nos preceitos smithianos, tendo a China e Índia como uma das possibilidades de hegemonia. 
os ciclos, genovês, holandês, inglês e americano, respectivamente. Esse quadro histórico mostra uma retração do capital em sua forma rígida (materializado na produção) e, em sua forma flexível (financeira) se movimenta em escala internacional através de transferências de um Estado nação para outro, caracterizando-se a transição entre os ciclos sistêmicos de acumulação.

A dinâmica dos ciclos sistêmicos ocorre através dos vetores da economia e da política. No âmbito econômico temos o natural processo de produção e reprodução ampliada que, em determinadas circunstâncias de ordem tecnológica e/ou social e política, saturam-se as condições de maximização do lucro real, levando o capital a priorizar a sua capacidade multiplicativa através das finanças. O vetor político pauta-se pelos conflitos de hegemonias entre estados nações em que tem sido recorrente na história as situações de "caos sistêmicos", ${ }^{8}$ resultando em demandas sociais de algum tipo de ordem, permitindo-se a presença de um novo Estado hegemônico. A conjunção desses dois vetores explica o fim e o início de cada um dos ciclos sistêmico de acumulação (CSA), pois dadas as condições para as expansões produtivas (EP) e os seus declínios, iniciam-se as crises sinalizadoras em (s) com as expansões financeiras (EF) através das transferências do capital da nação em declínio para o novo e emergente Estado nacional, que decola a sua fase de expansão produtiva (EP), e assim sucessivamente.

\section{Integração mundial e padrões tecnológicos}

Os padrões tecnológicos da "mecânica" e da "eletricidade e eletrônica" deram suporte ao terceiro ciclo sistêmico e parte do quarto. As condições, formas e gerenciamento da produção, bem como o alcance espacial da integração econômica entre as nações pautaram-se através de duas grandes fases: uma primeira, no $3^{\underline{0}} \mathrm{CSA}$ com a predominância da integração do comércio internacional entre as nações, configurando economias de Estados nações voltadas para o mercado exterior; uma segunda, no final do $3^{\circ}$ CSA e no $4^{\circ}$ CSA, a integração se deu através da predominância dos fluxos internacional de capitais produtivos, inicialmente dando suporte a exploração de matérias primas nas regiões atrasadas, e depois através da migração de capital visando criar mercados internos nessas regiões.

Essa seção faz uma síntese dos três primeiros ciclos com o propósito de mostrar a natureza, motivação e forma de integração internacional em cada período.

8 Trata-se de momentos de conflitos além do limite tolerável que desemboca em guerras entre Estados nações. 
Esses ciclos mostram a expansão e integração entre as nações e a hegemonia de um determinado Estado nacional, sendo favorecido pelas invenções técnicas e científicas de suas épocas e, de forma mais robusta, a integração sob a liderança inglesa, devido a $1^{0}$ e a $2^{o}$ Revoluções industriais que facilitaram o aumento do espectro espacial da então economia mundial que se baseou nos fluxos de comércio e de capital.

\subsection{Antecedentes}

Os dois primeiros ciclos referem-se ao final e o início dos períodos medieval e moderno, respectivamente. Foi uma época em que vários acontecimentos relevantes contribuíram para o seu desenvolvimento, a exemplo: da base técnica e científica com as invenções da prensa móvel gráfica, o telescópio, o microscópio, etc.; do enfraquecimento do feudalismo aos modos dos cavalheiros medievais; das expansões do comércio utramarinas; da reforma religiosa; e da nova cultura traduzidas pelo período renascentista.

Nesse cenário, o $1^{\circ}$ CSA situando-se nas CEI (Florença, Veneza, Gênova e Milão) apoiou-se através de quatro pilares na interpretação de Arrighi (1996; p. 37-39): na economia, pela adoção da lógica capitalista (DTD') por meio de uma "oligarquia mercantil" que norteava o poder estatal; na política, pelo equilíbrio de poder entre as cidades Estados, evitando a ingerência da lógica territorialista (TDT"); na guerra, pela introdução do soldo militar, gerando mercado e redução de custo da guerra; e na diplomacia, pela busca de conhecimento e informação, formando redes diplomáticas. Com a expansão e o declínio comercial dos séculos XIII e XIV e a subsequente expansão das finanças, ${ }^{9}$ se efetiva o primeiro ciclo sistêmico, o qual marcou por uma fase de expansão material e comercial com equilíbrio competitivo e uma fase final de excessiva concorrência que desembocou em guerras entre as cidades italianas que duraram cem anos. ${ }^{10}$ Esses conflitos caracterizam o caos que evidencia a crise sinalizadora desse ciclo, resultando na alienação do Estado pelos financistas, a exemplo da Casa dos Médici em Florença e Casa di San

9 Sendo para Arrighi o "ponto zero" do desenvolvimento do capitalismo com abrangência mundial, caracterizando-se por uma divisão internacional do trabalho e relações cooperativas entre as cidades estados, segundo as especializações e domínios de mercados: Florença e Milão atuavam em rotas terrestres e se dedicaram a produção de bens têxteis e de metais, respectivamente; e Veneza e Gênova atuavam em rotas marítimas com especializações em especiarias e sedas, respectivamente.

10 A outra guerra de cem anos anglo-francesa de 1337 a 1453 também contribuiu para o declínio da produção têxtil de Florença influenciando a perda do dinamismo comercial do ciclo. 


\section{Giorgio em Gênova. ${ }^{11}$}

A referência à Gênova como principal cidade Estado da CEI do $1^{\circ}$ CSA deve-se, segundo Arrighi (1996; 111-130), aos seguintes fatos: a) de ter tido êxitos nas expansões materiais e financeira; ${ }^{12}$ b) a Casa di San Giorgio (associação de financistas) oriundo da burguesia mercantil urbana, não assume a gestão do Estado, como ocorrera nas outras cidades; c) a ação do capital se configurou por mercados e estruturas de acumulação mais flexível; d) pela introdução da ideia da "moeda forte", atrelando as transações comerciais com troca de moedas em ouro de peso fixo. Com o declínio das oportunidades de comércio e a alta liquidez dos mercadores urbanos genoveses, estes aproveitam a situação da Península Ibérica através dos governos territorialistas da Espanha e Portugal, ${ }^{13}$ sendo a solução para a sua proteção e alocação de seu capital, formando no século XVI um grupo de banqueiros mercantis chamado de nobili vecchi que se tornou líder nas altas finanças europeia. Não obstante, com as longas e diversas guerras envolvendo a Península Ibérica, ${ }^{14}$ caracterizou-se a fase do "caos" e em consequência se apresenta um novo estado hegemônico, a Holanda.

$\mathrm{O} 2^{\circ} \mathrm{CSA}$, sob a hegemonia da Holanda, foi o único Estado dentre os quatros ciclos que se pautou pela gestão da liderança aberta, pois exportava seus métodos de governo e dos negócios para os seus liderados. Com o Tratado de Vestfália em 1648, a Holanda passou a liderar Estados nações criados sob essa nova ordem internacional que instituiu o conceito de estados soberanos. ${ }^{15}$ Diante das turbulências da concorrência entre os capitalistas e a luta territorialista da Espanha, os ventos sopraram para a Holanda, tendo em vista determinadas circunstâncias e estratégias adotadas, ou seja: a) fundiu duas formas de ação já realizadas, por Veneza, que se incumbiu de gerir o Estado e a guerra e, por Gênova, que utilizou a estratégia de expansão mundial através de intercâmbios nos negócios com outros estados; b) pela posição de Amsterdan na condição de armazém e entreposto comercial; c) o controle e alta liquidez em capital; d) a criação de uma bolsa de valores com elevados

\footnotetext{
11 Os excedentes de capital eram investidos em guerras e bens culturais, estes financiando a era renascentista italiana. Com o declínio da lã e o fracasso dos primeiros banqueiros florentinos ao financiar as guerras, aparecem os Médici que se tornam os maiores financistas de Florença, em razão dos seguintes motivos: ocuparam os espaços vazios da crise; fizeram escolhas seletivas para quem financiar, especialmente ao papado; teve a habilidade em decidir onde investir; tirou proveito do embate entre as visões territorialista e capitalista. De forma similar, Veneza e Milão passaram pelo mesmo processo. Com a crise sinalizadora, os financistas dessas três cidades se diluem, ressalvando-se Gênova que se aproveita de todo o primeiro ciclo sistêmico do início ao fim. (Arrighi, 1996; 87 - 111).

12 Iniciado por uma aristocracia rural e mercantil e que com a crise comercial se volta para os seus feudos e não faz concessão e proteção à burguesia urbana que passou a gerir alta liquidez monetária.

13 Que buscavam novas rotas de comércio para a Índia e a China visando romper o monopólio dos venezianos no mediterrâneo que haviam expulsado os genoveses desse mercado.

14 A Espanha, como o então Estado mais forte, mantendo-se nos padrões medievais de governar e buscando o domínio territorial de outras nações, gerou conflitos e surgiu o "caos sistêmico" abrindo, espaço para a Holanda, que já despontara como uma liderança moral e intelectual entre os estados dinásticos europeus.

15 Esse tratado inaugurou o moderno sistema internacional ao acatar noções e princípios tais como o de soberania estatal e o de Estado nação.
} 
fluxos de capital e flexibilidade nas transações; e) a internalização e redução dos custos de proteção através de uma organização territorialista da própria Holanda, casa de Orange, que defendiam os comerciantes de incursões bélicas; f) e as companhias de comércio e navegação que além de sua atividade fim, atuavam também nas guerras e como representante do estado holandês. ${ }^{16}$ (Arrighi, 1996; 130-148)

O modelo de hegemonia da Holanda por ser aberto, pois onde fincava seu domínio faziam-se investimentos e adotavam as práticas novas de gestão dos negócios, do Estado e da guerra, diga-se, introduzia-se a sua própria via de desenvolvimento. Esse modelo criou as condições para o nascimento dos variados tipos de mercantilismo que se tornaram competitivos e foram minando a hegemonia holandesa. Essa nova realidade associada com as lutas territorialista e capitalista configurou-se no "caos sistêmico" que foi influenciado pelos seguintes acontecimentos: conflito anglo-francês, independência americana, revolução francesa, guerras napoleônicas, etc. Esses fatos deram margem para o então florescimento da Inglaterra como o novo estado hegemônico. Dessa forma, a Holanda canalizou seus esforços para as altas finanças como forma de sobreviver, provocando a substituição do centro do capitalismo em Amsterdam para Londres. Encerra-se o $2^{\underline{0}}$ CSA e se inicia um novo ciclo sistêmico de acumulação agora liderado pela Inglaterra.

\subsection{Revoluções industriais e integração econômica}

Sob uma nova realidade tecnológica baseada na "mecânica" e na "eletricidade" ocorreu o $3^{\circ} \mathrm{CSA}$ abrangendo as duas primeiras revoluções industriais, fazendo-se hegemônica neste ciclo, a Inglaterra . De acordo com a interpretação de Arrighi (1996; 47-58), três fatores caracterizaram o caminho para o êxito inglês: a) diante do insucesso da França e Inglaterra - estados territorialistas de subjugar o então estado capitalista, a Holanda, ambas as nações procuraram exercer o domínio do oceano Atlântico; b) com o aprendizado da gestão dos negócios holandeses, esses países no século XVIII introduziram um tipo de mercantilismo em que se fazia a síntese das lógicas capitalista e territorialista; ${ }^{17} \mathrm{c}$ ) no contexto do então caos sistêmico introduziu-se o conceito abstrato do livre comércio como fator norteador da nova ordem mundial.

Esse último aspecto gerou um sistema mundial caracterizado de "imperialismo

16 Como afirma Arrighi (1996; 155), o tripé baseado no entreposto comercial, de liquidez de capital em Amsterdam e as Companhias das Índias Orientais e Ocidentais, explica a acumulação ampliada da hegemonia holandesa.

17 As bases que compuseram essa prática envolveram a "colonização direta" através da criação de colônias permanentes; a "escravatura capitalista" resolvendo o problema da escassez de mão-de-obra; e o "nacionalismo econômico", possibilitando a mobilização da então sociedade civil no suporte das gestões de governos e da guerra. 
de livre comércio" ou do então capitalismo concorrencial, o qual foi calcado com base nas relações entre os estados por interesses de comunidades civis e da classe dos proprietários de cada nação, e não, sob os desejos e controle dos monarcas, configurando-se em um "nacionalismo democrático". ${ }^{18}$

Essa nova ordem feriu a concepção do tratado de Vestfália, pois os princípios de conduta passaram a ser norteados por uma autoridade superior e intangível da economia liberal - mercado livre regido pela mão invisível - entre e em cada nação, diferindo daquele tratado que propunha a inexistência de qualquer tipo de autoridade superior ao sistema de estados soberanos. Esses princípios de linhagem smithiana, praticados pela Inglaterra e associado aos processos de produção mecanizados foram difundidos em todo o mundo e tornaram-se referências para o ideário da supremacia inglesa.

Em seu estágio inicial, a indústria foi movida com uso de máquina motriz à base do carvão, motores a vapor em máquinas, e a integração espacial pelas vias ferroviárias e marítimas, tratando-se da $1^{\underline{0}}$ Revolução industrial. Nesse período, a composição das mercadorias agregava baixo nível de capital e o mercado sendo concorrencial, ${ }^{19}$ refletiu-se nas relações econômicas internacionais, tornando o comércio de produtos de consumo final o meio para a integração mundial. Com o crescimento da indústria mecanizada, intensificou-se e diversificou-se o uso dos bens de capital, propiciando o auto abastecimento desse setor e destinando-se para uma maior variedade na produção do setor de bens de consumo. Este fato proporcionou a expansão de mercados e o acirramento da competição, estimulando a proliferação do comércio e da produção de bens de consumo no mundo. Efetiva-se a integração do mercado internacional, dado que as regiões não industrializadas elevaram a produção de matérias primas visando gerar recursos e obter bens industriais, em especial no mercado inglês, que detinha praticamente o monopólio dessa atividade. Esse cenário mostra que a abertura e liberdade do mercado da Inglaterra criaram redes internacionais liderados por esse Estado, caracterizando uma integração interestatal por influência exógena, diga-se o "mercado externo" de cada nação. Tratou-se do período da predominância dos ganhos em torno do capital comercial.

Em um segundo momento, que se inicia por volta dos fins do século XIX, exportou-se muito capital da Inglaterra, caracterizando-se como o período do capitalismo monopolista.

18 Ressalta-se para a exclusão da classe dos não proprietários, especialmente da massa trabalhadora, expressando manifestações intelectuais que desembocou nas obras de Karl Marx, especialmente em seu "O Capital".

19 A dotação de capital no setor produtor de bens de consumo era maior do que no setor de bens de produção, dado que este tinha uma caráter de oficinas artesanais e suas máquinas e equipamentos eram usados para a produção de bens de consumo. 
Tratou-se da época da $2^{0}$ Revolução industrial, em que todos os setores da indústria - produção e consumo - fizeram uso de máquinas e equipamentos elétricos. Época em que foram incorporados em todas as atividades de produção os motores elétricos e de explosão, implicando no uso de um alto nível de capital para se produzir bens de produção e mercadorias de consumo, propiciando a formação de monopólios no âmbito nacional e internacional. Diante da agregação de alto teor de capital no processo de produção verificouse uma grande intensidade nas exportações do capital produtivo inglês para o resto do mundo, especialmente para as regiões mais atrasadas. Tratou-se do estágio em que o capital produtivo registrou mobilidade externa e intensificou a sua concentração em nível mundial.

Esse cenário refletiu a expansão da atividade siderúrgica através das construções de vias férreas e navios a vapor e constituídos de aço, bem como o impulso na indústria têxtil, tornando o setor de bens de capital inglês a expressão da expansão do capitalismo em escala internacional. A queda da taxa de lucro interna corroborou para o crescimento vertiginoso das exportações inglesas de bens de capital e a consequente formação de uma rede econômica mundial, tendo como centro a Inglaterra. Esse período do desenvolvimento e expansão mundial do capitalismo assentou-se com base em ganhos da integração comercial entre as nações através das correspondentes produtividades e dotações de fatores de produção de cada Estado nacional.

Na fase de expansão material desse ciclo sistêmico de acumulação ocorreu uma depressão econômica durante o último quartil do século XIX, resultante da grande concorrência de mercado e redução dos preços que acarretou a queda nas taxas de lucros das empresas industriais e comerciais. Esse cenário desestimulou novos investimentos na expansão produtiva do ciclo, o que provocou a procura por ganhos financeiros e bancários dando início à crise sinalizadora do $3^{\circ}$ CSA. Entra em cena os Rothschild como parte da rede financeira germano-judaica e de concepção cosmopolita, mas com forte vinculação com o Tesouro e o Banco da Inglaterra que teve atuação ativa entre 1866 a 1930. Não obstante, após esse craque, apresentou-se um novo momento conhecido como "la belle époque", que Arrighi (1996; 163-179) explica com base em pelo menos dois aspectos: a) a competição pelo capital excedente sob a forma de acumulação financeira da fase anterior, incentivando a especulação e o seu desdobramento na alta dos juros; b) em razão da competição no que tange as fatias de mercado internacional, resultando no aumento de gastos militares que desembocou na primeira guerra mundial do século XX e na subsequente depressão econômica de 1930. Este quadro internacional se caracterizou como a fase do caos sistêmico e o prenúncio de um novo ciclo liderado pelos Estados Unidos. 
Observa-se nesses dois momentos configurados nos padrões tecnológicos que sustentaram as $1^{\varrho}$ e $2^{\circ}$ Revoluções industriais, que a expansão internacional do capital e a sua consequente integração econômica entre as nações se deram a partir de duas características: uma, através da polarização de um Estado nação, a Inglaterra; e outra, através do estímulo exógeno, segundo o predomínio do mercado externo de cada nação.

\section{Globalização e novas tecnologias}

O $4^{\circ}$ CSA, liderado pelos Estados Unidos da América (EUA) se iniciou ancorado nos padrões tecnológicos da $2^{\circ}$ Revolução Industrial e, atualmente, opera com base na tecnologia da microeletrônica e automação, configurado nos chips que representam um ícone da $3^{\circ}$ Revolução Industrial. As formas de gestão e produção, e o alcance espacial da integração econômica se deram por influência endógena no primeiro momento e, atualmente, pauta-se através de influências exógenas e endógenas simultâneas, implicando tanto na fragmentação da integração entre regiões de distintas nacionalidades, ${ }^{20}$ quanto na composição de blocos de Estados nações.

A subseção seguinte aborda o intervalo de 1870 a 1930, que representa a transição das hegemonias da Inglaterra para os EUA, caracterizando-se pela fase de elevada liquidez internacional. Trata também das situações da economia a partir de 1930 até o fim da II Guerra Mundial e, no período após 1945, praticaram-se os preceitos keynesianos na economia ocidental e, com os seus resultados, esse período ficou conhecido como os anos dourados do capitalismo no século XX. Ambos os períodos são considerado no modelo de Arrighi de expansão material. A subseção final abrange a economia a partir de 1970 que ficou conhecida como a fase da então globalização contemporânea, e que no modelo de Arrighi trata-se da atual crise sinalizadora, sob a predominância da acumulação financeira.

\subsection{Antecedentes}

Com os sinais de declínio inglês a Alemanha e os Estados Unidos apresentaram-se como sucessores da nova hegemonia. Diante das pretensões territorialistas alemã, baseada em sua industrialização e inovação do setor bélico, como coloca Arrighi (1996: 59-65), deram-se início os conflitos entre os Estados europeus, configurando um novo caos sistêmico. Os EUA, tendo uma vasta área geográfica, praticaram um territorialismo interno sob bases capitalistas

20 Que se aproxima do conceito de Estados regiões em Ohmae (1996). 
às expensas do externo. Isto se deveu à importância da formação e dinâmica de seu mercado nacional aberto para a entrada de mão de obra, capital e empreendedores. Essa prática contribuiu para a demarcação geográfica da unidade nacional baseada em estados relativamente independentes e para o dinamismo econômico pautado na economia de livre mercado.

Tratando-se do período da crise sinalizadora do $3^{\circ}$ CSA iniciada em torno de 1870, constatou-se uma alocação nos EUA de grandes volumes de excedente do capital monetário inglês, tornando a Inglaterra detentora de direitos em ativos americanos. Não obstante, com a eclosão da ${ }^{\circ}$ Guerra mundial na arena europeia, reverteu-se esse quadro tendo em vista os Estados Unidos se tornar fornecedores junto ao Estado inglês, de equipamentos, material bélico, máquinas e matérias-primas. Este fato resultou, inicialmente, em superávits comerciais para os EUA, que implicou na apropriação dos ativos das aplicações inglesas, gerando também superávits em suas transações correntes com os juros dos ativos. Apesar de esse cenário ter sido favorável à economia americana, esta Nação não tinha ainda adquirido maturidade no manejo das finanças, por isso a comunidade financeira de New York, especialmente a casa de Morgan, atrelou-se à City londrina, dado que a Inglaterra ainda possuía grandes reservas em ouro.

Essa situação contribuiu para a volta, em 1926, do padrão ouro, visando o reestabelecimento do sistema monetário mundial aos moldes do período préguerra, que se sustentou até a grande depressão de 30. Não obstante, o que se verificou foi o acontecimento da crise terminal do $3^{\circ}$ CSA, pois em razão da boa posição dos EUA nos anos 20, do afluxo para esta Nação de elevados volumes de ativo em moeda estrangeira em pouco tempo, associado, aos investimentos americanos no exterior e, às tentativas das nações em ajustar suas moedas ao padrão ouro; o movimento do capital assume as formas especulativas e atinge um ponto de saturação em que os EUA suspenderam os financiamentos e investimentos no exterior, caracterizando um descolamento entre os ritmos de acumulação material e financeira. Em consequência ocorreu a debâcle econômica e social provocada pelo Big Crash de New York em outubro de 1929, mais conhecida como a grande depressão econômica de 1930. Este fato resultou na alta do juro, estagnação produtiva, e no fim do padrão ouro atrelada à libra esterlina, em 1931.

Além desses acontecimentos, Arrighi (1996: 290-291) relata que o modelo industrial inglês e a sua relação "extrovertida" com a economia mundial, ${ }^{21}$ pautou-se pela integração econômica complementar entre a Inglaterra e as

21 A organização da indústria inglesa apoiou-se em empresas especializadas e desintegradas quanto às produções de bens de capital, matérias-primas e de bens de consumo final. 
suas colônias e nações estrangeiras. Diferentemente, os EUA posicionaram-se de forma "autocentrada”, que se caracterizou por um modelo de organização industrial integrado verticalmente, tal que a sua inserção internacional se deu através de grandes corporações empresariais que internalizavam em torno de si a economia mundial. Tratou-se da época dos grandes "Trustes" americanos sinalizando para o aparecimento das futuras empresas multinacionais. Este modelo industrial obteve maior êxito do que o modelo industrial alemão ${ }^{22}$ no sentido de substituir a hegemonia da Inglaterra, pois em virtude do grande território dos EUA, as economias internas da integração vertical compensavam as suas menores economias externas em relação às da Inglaterra, enquanto que na Alemanha o seu modelo de integração horizontal não gerava essa compensação.

A partir de 1930 um novo ideário começa a ser gestado, tanto pela política do New Deal nos Estados Unidos da América como pela “Teoria Geral” de Keynes, que reformula a forma de se conceber a então economia de mercado através do conceito do welfare state. O período inicial de 15 anos que vai até ao final da $2^{0}$ Guerra mundial pautou-se, pelo lado europeu, com a ascensão do eixo nazifacista, em que o nacionalismo se tornou dominante e, portanto, as economias das nações se endogenizaram. Esse cenário levou ao segundo conflito armado em escala internacional do século XX, com a eclosão da $2^{\underline{a}}$ Guerra mundial. Pelo lado americano temos o New Deal, gestão econômica pública de caráter assistencialista, visando atenuar os efeitos da depressão da economia, bem como os ganhos econômicos oriundos da guerra, por ser a então economia mais forte da época entre as nações aliadas contra o eixo. Tratou-se de um período em que a integração da economia mundial sofreu um revés em razão da busca de ajustes e conflitos de e entre Estados nações.

No pós-guerra, iniciou-se uma reestruturação profunda no espectro político e econômico. Uma nova ordem mundial foi gestada sob a hegemonia americana, que no final dos anos 40 detinha o monopólio da liquidez internacional. Foi posta na agenda a visão "unimundista” de Roosevelt. ${ }^{23}$ Contudo, a sua prática foi reduzida à concepção da doutrina Truman ${ }^{24}$, em que o mundo era visto de forma dividida em duas áreas de influência ideológica, uma liderada pelos Estados Unidos, o lado ocidental com o projeto capitalista, e outra liderada pela União das Repúblicas Socialistas Soviéticas (URSS), o lado oriental com a proposta comunista. ${ }^{25}$ Mudanças substanciais foram introduzidas em várias

\footnotetext{
22 Este se caracterizou pela integração horizontal através de empresas concorrentes, diferindo do modelo inglês de integração horizontal complementar.

23 Que nada mais foi do que uma extensão internacional do seu New Deal e que se baseava no pensar de "que somente um governo grande, benevolente e competente, poderia garantir a ordem, segurança e a justiça para os povos,“.(Arrighi, 1996: 285).

24 Presidente dos EUA que sucedeu Roosevelt.

25 Diante da bipolaridade de hegemonias que se traduziu no período da "guerra fria", este artigo trabalha com a hegemonia dos Estados Unidos pelo lado ocidental do globo.
} 
áreas através da criação de vários organismos internacionais, a exemplo da ONU, FMI, BIRD, e tantos outros. Essa concepção demonstra um rompimento com a economia ortodoxa e segue um roteiro keynesiano, com o welfare state. Com a criação do FMI, através do acordo de Bretton Word, as finanças saem do controle privado de Wall Street e passa para o público através dos Bancos Centrais de cada Estado nação.

Nesse contexto, o ponto de partida prático para uma nova ordem econômica foi a reconstrução da Europa e do Japão com o Plano Marshall. A lógica da integração econômica mundial durante as décadas de 50 e 60 se deu com o fortalecimento e criação de mercados internos em Estados nacionais, sendo motivado pelo ponto de vista endógeno para a integração através dos fluxos de investimentos diretos externos entre as nações. Nessa fase muito se pensou sobre o desenvolvimento sob a influência de gastos públicos, compatibilizando-se com as necessidades de fluxos de capitais entre os Estados nações, bem como pela relevância das empresas multinacionais.

O declínio da expansão material do $4^{\circ} \mathrm{CSA}$ começou a se manifestar no final dos anos 60, e pelo lado financeiro observou-se uma integração das finanças internacionais, tendo como ator central as empresas multinacionais americanas, pois proporcionaram as migrações de grandes contingentes de capitais para a Europa, passando a gerar conflitos entre o estoque da dívida externa dos EUA a sua disponibilidade de reservas em ouro, tornando-se 1968 um momento agudo desse conflito. Pela ótica institucional e política, registra-se a perda do controle regulatório por parte dos Estados Unidos sobre a expansão financeira mundial. (Arrighi; 309-314). Em paralelo a esses acontecimentos, se apresentou o processo de gestação da $3^{\mathrm{a}}$ Revolução Industrial, que promoveu mudanças estruturais nos processos de produção e um salto na evolução dos meios de transportes, dos padrões de comunicação através da tecnologia de informação e da atual convergência tecnológica à base de microchips, tornando o mundo digitalizado.

\subsection{A globalização e o modelo de Arrighi}

Em 1970 é iniciada a crise sinalizadora do $4^{\circ}$ CSA. A globalização contemporânea ancora-se no aspecto estrutural do funcionamento da economia, a qual incorreu em um redimensionamento profundo que resultou em uma nova dinâmica de acumulação capitalista, refletindo em novas estratégias de integração mundial. Em termos de fatos econômicos conjunturais, acontecimentos marcantes nortearam as últimas décadas, contribuindo para a 
compreensão de mudanças significativas em relação aos fatos recorrentes de crises sinalizadoras anteriores.

\subsubsection{Fundamentos da nova globalização}

Os aspectos estruturais envolvendo os processos de produção, gestão e das estratégias de integração do mercado mundial, tem o propósito de mostrar do por quê podemos admitir a existência de uma nova globalização. Pari passo à avaliação estrutural faz-se uma síntese sobre momentos relevantes de ordem conjuntural que tem acompanhado a atual crise sinalizadora.

\subsubsection{Aspectos estruturais}

As novas tecnologias ancoradas nos "chips" tem sido a base da $3^{\text {a }}$ Revolução Industrial. Os processos produtivos são constituídos de capacidades instaladas compostas de máquinas e equipamentos polivalentes e mundiais, ${ }^{26}$ tornando o sistema de produção flexível. Os métodos de gestões empresariais são dotados de novos desingns, visando atender a economia de fluxos fundada na precisão de tempo e na otimização de unidades de insumos e do produto final, proporcionando maior eficiência e dinamismo nos processos administrativos e de distribuição do produto.

Além das novas tecnologias e de seus efeitos nos processos produtivos através da escala, diversificação, simultaneidade e agilidade; as novas configurações das atividades industriais envolvem também os seguintes aspectos: a) os processos de desintegração vertical da indústria com um novo modus operandi através de subcontratações de empresas de serviços e de sua cadeia de fornecedores, de spin off, etc., tornando-se flexíveis às relações entre e intra indústria; b) o mercado de trabalho com a exigência de mão de obra qualificada e multifuncional e o mercado de produto final que requer bens de elevado poder competitivo; c) as alocações de empreendimentos passam a ser norteado por locais dinâmicos, os quais se viabilizam através de investimentos em infra estrutura física, em bases institucional e jurídica, e em capital humano, de forma a reduzir custos de transações.

26 É polivalente por desempenhar várias e distintas funções de forma simultânea e é mundial em razão de sua capacidade de produção transcender as demandas locais e nacionais. 
Trata-se de uma configuração em que pelo lado da expansão material (EP), as novas tecnologias propiciam a sua flexibilização das estruturas produtivas, vindo a atenuar a rigidez e concretude da produção e do comércio, reduzindose perdas e estimulando ganhos de rentabilidades de investimentos reais na economia.

O alcance e forma de atuação espacial do capital são norteados pela capacidade competitiva e inserção de mercado. Nesse contexto, os ganhos capitalistas passaram a ser exigida a partir do conceito das vantagens competitivas que, em função do incremento da concorrência, são motivados pela geração de rendas tecnológicas, estas obtidas no lado real da economia pelas incessantes inovações e alto teor técnico internalizado no processo produtivo e no produto. ${ }^{27}$

Nesse contexto, o atual capitalismo globalizado requer como meio intrínseco para o seu funcionamento a ligação orgânica da pesquisa e conhecimento de inovações técnicas com o processo de produção e o mercado, além das próprias mudanças nas estruturas produtivas das empresas e indústrias e da distribuição e expansão espacial de seus produtos e serviços em escala internacional. No âmbito espacial observa-se uma diluição de fronteiras territoriais - regional e nacional -, em razão da integração do comércio e dos fluxos de investimentos diretos em escala mundial serem teleguiadas pela busca de rendas tecnológicas.

As diluições de fronteiras e a integração econômica tem se dado através de dois cenários: a) entre regiões específicas e competitivas que tenham alguma autonomia econômica em relação ao Estado nação; b) no contexto da formação de blocos econômicos através das integrações de Estados nacionais, que viabilizam a criação de mercados regionais em escala internacional. Considerando que na economia atual o que interessa ao capital é que o seu produto ou serviço seja mundial, tal que seja competitivo em mercados regional, nacional e internacional, bem como viabilize ganhos baseados nas rendas tecnológicas. Dessa forma, a compreensão da então globalização contemporânea passa de forma simultânea pelos fatores externos e internos.

O capital através de seus investimentos e os blocos de Estados nações criando mercado têm um movimento convergente. Esse cenário estimula o capital buscar tanto regiões competitivas com baixos custos de transações, como mercados regionais criados por blocos econômicos regionais. Isto se configura em um modelo de economia global pautada na integração fragmentada e em 
blocos econômicos de Estados nações.

Diante dos fatos descritos, apreende-se que a configuração do capitalismo contemporâneo fundamentado nas novas tecnologias tem proporcionado um processo de reprodução material (EP) de forma bastante flexível, bem como na esfera financeira (EF) têm aparecido inovações de produtos, a exemplo de mercados futuros calcados em vários tipos de derivativos. ${ }^{28} \mathrm{O}$ mundo financeiro passou a diferir, substancialmente, dos modelos de acumulação passados que caracterizaram os três primeiros CSAs, pois com a internalização desse novo padrão tecnológico no setor e da introdução de inovações e diversificação de produtos financeiros; a mobilidade de capital se tornou instantâneo e altamente flexível, implicando em mecanismos de ganhos financeiros, independente, de um único Estado nacional hegemônico, pois o que motiva a mobilidade do capital são as condições favoráveis de mercados especulativos.

A nova realidade da economia e o comportamento da mobilidade dos investimentos diretos externos, nas últimas décadas da atual crise sinalizadora, têm se diferenciado dos padrões rígidos de acumulação (DM) e das formas de concentração espacial do capital, voltados para os Estados nações hegemônicos, a exemplo dos ciclos sistêmicos de acumulação passados liderados por Gênova, Holanda, Inglaterra, e da fase de expansão material dos EUA. Apesar da ainda liderança dos Estados Unidos, especialmente em seu setor bélico, o que se supõe no mundo atual é uma tendência de diversificação da concentração do capital, sinalizando para algumas possibilidades de mudanças, a exemplo, da China ou de uma forma de hegemonia multipolar, que envolvam mais de uma nação. ${ }^{29}$

\subsubsection{Aspectos conjunturais}

Os anos de 1970 se iniciaram-se com o fim do sistema de câmbio fixo do acordo de Bretton Word que deu sustentação aos 25 anos do pós-guerra e de expansão material. A nova realidade econômica desta década conviveu com a desregulamentação do mercado financeiro que levou à intensificação da acumulação das finanças no mundo. O fim da paridade dólar-ouro se deu em razão da deterioração na credibilidade do dólar tendo em vista a sua emissão

28 As finanças passaram a ter novas categorias de produtos que refletem as inovações tecnológicas introduzidas no sistema bancário e financeiro.

29 Em Arrighi (2008), tem-se uma leitura de base smithiana sobre a economia chinesa e uma reflexão sobre a questão da nova hegemonia econômica. 
visando financiar o déficit comercial americano durante os anos 6o. Esse fato ficou conhecido como o dilema de Triffin ${ }^{30}$, que detectou problemas de consistência na capacidade dos EUA gerar liquidez associada a crescentes déficits da sua balança comercial, sem comprometer o lastro do dólar em ouro. Com o fim do câmbio fixo, o dólar deixa de ser uma moeda padrão de referência e passa a ser uma simples moeda de financiamento.

Tratou-se de um período em que a economia mundial se retraiu devido à conjunção de vários fatos, como as duas crises do petróleo de 1973 e 1979, a proliferação dos eurodólares e petrodólares, a liquidez mundial baseada em uma cesta de moedas, a existências de mercados off shore, e o choque da alta dos juros americanos em 1979 através do Plano Volker. ${ }^{31}$ Esses fatos retiraram dos Bancos Centrais o poder de controlar e regular o meio circulante da economia mundial e o regime de câmbio fixo. Em março de 1979, países da então Comunidade Econômica Europeia (CEE) criaram o Sistema Monetário Europeu (SME), visando manter algum controle e regulação sobre a taxa de câmbio, inflação e atentar para a unificação da moeda europeia a partir da composição de uma cesta de moeda baseada nas devidas proporções dos PNB dos países. A década de 80 se caracterizou por crise das dívidas externas de nações emergentes, especialmente da América Latina, e a consolidação econômica de nações do leste asiático, em particular Hong Kong, Cingapura, Formosa e Coreia do Sul, e com maior vigor e sustentação o Japão, que Arrighi (1996: 344-350) suscitou a hipótese de ser o provável beneficiado para a nova hegemonia.

Não obstante a exuberância da economia japonesa no pós-guerra e a sua significativa participação mundial na absorção de renda e capital, o que se verificou foi um alarme falso sobre a sua possibilidade de suceder os EUA como a nova Nação hegemônica e do início de um $5^{\circ}$ CSA. Isto se deveu ao fato dos Estados Unidos não ter seguido os padrões dos estados hegemônicos anteriores - Gênova, Holanda e Inglaterra -, pois em vez de exportar capital financeiro para o Japão, o que ocorreu foi uma atração de investimentos para a economia americana, especialmente do Japão no início da década de 80.

Com o acordo de Plaza em New York, no ano de $1985^{32}$, em que se decidiu pela desvalorização do dólar visando estimular a balança comercial americana, desmistificou-se a hipótese de hegemonia japonesa, além de que esta nação saiu prejudicada com a sua ajuda e parceria com os EUA. O capital exportado do Japão para os Estados Unidos, quando o dólar estava em alta, foi ressarcido após o acordo de Plaza com o dólar em baixa.

\footnotetext{
30 Economista belga radicado nos Estados Unidos, crítico do sistema monetário proposto em Bretton Word.

31 Então presidente do FED dos Estados Unidos.

32 Firmado pelo G7 (EUA, Inglaterra, Canadá, Itália, França, Japão e Alemanha).
} 
A partir da década de 90 aconteceram processos de fusões e incorporações de grandes empresas e, entres nações emergentes, se apresentaram crises de ataques especulativos - México, Ásia, Rússia, Brasil e Argentina. Tratou-se de uma década em que uma nova forma de movimento espacial do capital em escala internacional se consolidou, pois o seu objetivo foi direcionado para regiões competitivas e/ou vinculados a blocos econômicos.

Mais recentemente, nos anos 2000, a economia mundial passou por uma inflexão ascendente acompanhada de excesso de capital, caracterizando-se por uma fase de alta liquidez internacional. Não obstante, desde de $2007 \mathrm{se}$ iniciou nos Estados Unido uma crise em seu sistema de crédito imobiliário, com rebatimentos em 2008 no sistema financeiro internacional e na economia real, provocando um grande abalo nas economias desenvolvidas. No entanto, com a adoção de medidas de linhagem keynesianas no sentido de proteger determinadas empresas e atenuar o impacto na demanda, observa-se a partir de 2009 alguns sinais de recuperação.

\section{Considerações finais}

As análises de fatos históricos e atuais tendo como referência o estudo de Giovanni Arrighi "O longo século XX”, requer alguns comentários nesta conclusão. Enfatiza-se que se procurou desenvolver um texto que refletisse uma compreensão da atual realidade globalizada. Esse intento exigiu a adoção de uma âncora teórica e histórica que possibilitasse dar substância aos propósitos dessa iniciativa. $\mathrm{O}$ artigo partiu da ideia de que as novas tecnologias explicam as mudanças nas estruturas sistêmicas da economia contemporânea, quando comparadas com as estruturas passadas ancoradas em padrões tecnológicos rígidos. Dessa forma, levantaram-se questões sobre padrões de acumulação material da produção e do capital financeiro, de competitividade e integração de mercados globais, e uma breve incursão sobre a hipótese de um novo ciclo sistêmico de acumulação.

Como descrito ao longo do artigo, os CSAs traduzem modelos de reprodução econômica e de hegemonias de Estados nações sustentados na acumulação e expansão do capital financeiro. Considera-se como ponto zero da abrangência do capitalismo em escala mundial, o $1^{\circ}$ CSA que teve como protagonista as Cidades Estados Italianas (CEI) e, em particular, Gênova; o $2^{\circ}$ CSA foi liderado pela Holanda; no $3^{\circ}$ CSA o novo centro hegemônico do capitalismo passou a ser a Inglaterra; e no $4^{\circ} \mathrm{CSA}$ os Estados Unidos da América.

A hegemonia da Inglaterra qualitativamente se distinguiu dos ciclos anteriores - Gênova e Holanda - em razão da $1^{\underline{a}}$ Revolução industrial em que se inseriu os processos mecanizados e de reprodução material da produção. É 
neste ciclo que se configurou a forma mais acurada da integração econômica mundial baseada nas vantagens comparativas do comércio que, para alguns autores, é considerada também de globalização ou de fase da predominância do imperialismo do capital. O $4^{\circ}$ CSA sob a hegemonia dos Estados Unidos caracterizou-se por quatro fases: a primeira, de transição de hegemonias (1870 a 1930); a segunda, de ajuste endógeno após a depressão de 30 e de turbulências bélicas que desencadeou na $2^{\mathrm{a}}$ Guerra mundial (1930 a 1945); a terceira, uma nova ordem fundada no princípio do welfare state, que ficou conhecido como a idade de ouro do capitalismo (1946 a 1970); e a quarta, que começou a partir de 1970, sendo norteada pelas vantagens competitivas e que se enquadra na atual forma de globalização.

No estudo desses ciclos, observou-se que o capital financeiro tem sido o fio condutor de suas transições, caracterizadas pelas mudanças de um Estado nação hegemônica para outro estado, patrocinando-se as formas de integrações das nações. As diferenças estruturais entre os CSAs se deram em razão dos processos de inovações técnicas. Nesse contexto, a conclusão das indagações levantadas na introdução enfatiza os pontos importantes que diferencia as interpretações referentes a globalização passada e contemporânea.

A primeira indagação aborda a acumulação do capital sob a esfera produtiva. Em razão de Arrighi fazer uma interpretação da produção material em termos de rigidez e concretude, verificou-se que as novas tecnologias fundamentadas nos chips introduziram, no sistema produtivo uma capacidade instalada flexível provocando maior fluidez no processo de acumulação e reprodução material do capital, rompendo com os padrões históricos dos ciclos sistêmicos anteriores fundamentados na rigidez de suas expansões produtivas. A resposta dessa questão é afirmativa, pois as novas tecnologias fundamentadas na $3^{a}$ Revolução industrial tornaram os processos de acumulação e gestão da produção material flexível.

A segunda questão trata de padrões de competitividade e de diluição de fronteiras espaciais. A decisão de realização do investimento e de sua localização tem como pré-requisitos a organicidade do conhecimento em ciência e tecnologia com a esfera produtiva, propiciando a geração de renda tecnológica e a busca de regiões dinâmicas. Dado que as rendas tecnológicas se pautam pelo teor de incorporação de inovações nos processos produtivos e no produto, favorecendo ganhos capitalistas e proporcionando-se vantagens competitivas; a resposta dessa questão ratifica que os atuais padrões de competitividade de empresas globais e Estados nações são norteados pela busca de rendas tecnológicas e regiões competitivas que caracterizam a diluição de fronteiras 
geográficas.

Na terceira indagação se pergunta sobre as características da integração regional na então economia globalizada. Deduz-se que o período iniciado em 1970 se distingue das formas passadas de integração mundial. Isto se deve à existência de mudanças estruturais nos processo de produção, de gestão, de distribuição e de alocação de investimentos. Em consequência, se rebate em formas de integração fragmentada entre regiões de nações diferentes na linha do conceito de Estados regiões de Ohmae (1996), bem como através da formação de áreas regionais de comércio, na linha de Balassa (1964). Dessa forma, confirma-se a questão levantada na introdução de que a globalização apoia-se através da integração regional fragmentada e em blocos regionais de âmbito internacional.

A quarta enfoca a questão da autonomia e mobilidade do capital financeiro. Abordando a questão financeira, mostrou-se que a sua acumulação que já era tida como flexível, foi bastante intensificada em razão da diversidade de produtos novos que têm sido gerados em razão das novas tecnologias dos sistemas online, propiciando alta especulação em grandes variedades de bens financeiros, a exemplo de produtos nos mercados futuro envolvendo todo tipo de derivativos financeiros e reais. Neste sentido, a diversificação financeira associada com as novas tecnologias criou as condições para a sua superacumulação e mobilidade internacional, as quais são baseadas em contratos de natureza especulativa que resultou no total descontrole e descolamento com a atividade real e na grande dificuldade de regulação pelos bancos centrais.

A quinta pergunta indaga se é possível ocorrer um $5^{\circ}$ CSA. Como é de se esperar, a resposta é inconclusiva, pois concluo que o mundo atual se encontra em plena crise sinalizadora do $4^{\circ}$ CSA. Apesar de Arrighi (2008) em seu último livro, deduzir pela precipitação da crise terminal e da possibilidade de um novo modelo de hegemonia liderado pela China. A análise feita induz para a hipótese de que se vier ocorrer um novo ciclo sistêmico de acumulação, este poderá acontecer sob uma expansão material flexível em razão das novas tecnologias e, diante dos sinais da atual crise econômica, é de se esperar que se apresente uma nova arquitetura para o sistema financeiro de tal forma que se possa ter algum grau de regulação em sua reprodução e expansão internacional.

Concluindo essa reflexão, o artigo caracterizou-se por um resgate analítico dos processos históricos com base no modelo dos ciclos sistêmicos de acumulação e buscou como propósito trazer algumas questões contemporâneas para serem pensadas à luz da densa obra de Giovanni Arrighi, "O longo século $X X$ ". Dessa forma, tentou-se seguir sua base metodológica dos ciclos sistêmicos de acumulação e fazer algum link com a questão tecnológica e, em especial, com as atuais tecnologias para explicar a hipótese de uma nova forma de globalização econômica. 


\section{Referências}

ACOCELLA, Nicola. Economic Policy in the Age of Globalisation. Cambridge University Press (2005).

AUED, Idaleto, M. \& CAPANA, Samya. "Concepção de História em Fernand Braudel e Immanuel Wallerstein: uma análise maxiana”. Revista Virtual de Cadernos de História URL: www.ichs.ufop.br/cadernosdehistoria/anteriores.php

DUMÉNIL, Gerard \& LEVY, Dominique (2002). “The profit rate: where and how much did it fall? Did it recover? (USA 1948-2000)". Review of Radical Political Economics, 34: 437-461, North-Holland.

ARRIGHI, Giovanni. (1996) O longo século XX. São Paulo: Ed. UNESP.

ARRIGHI, Giovanni. (1997) A ilusão do desenvolvimento. Rio de Janeiro: Ed. Vozes.

ARRIGHI, Giovanni. (2008) Adam Smith em Pequim: origem e fundamentos do século XXI. São Paulo: Boi tempo.

BALASSA, Bela. (1964) Teoria de la integración econômica. México: Facultad de Economia de La Universidade Nacional Autónoma.

BRAUDEL, Fernand (1998). Civilização material, economia e capitalismo, séculos $X V-X V I I I$. São Paulo: Ed. Martins fontes.

HILFERDING, Rudolf (1985). O capital financeiro. São Paulo: Abril Cultural. (Os Economistas).

HIRST, Paul; THOMPSON, Grahame (1998). Globalização em questão. Rio de Janeiro: Ed. Vozes.

LÊNIN, Vladimir I (1979). O imperialismo: fase superior do capitalismo. São Paulo: Ed. Global.

MANDEL, Ernest (1982). O capitalismo tardio. São Paulo: Abril cultural.

OHMAE, Kenichi (1996). O fim do Estado nação: a ascensão das economias regionais. Rio de Janeiro: Ed. Campos.

OHMAE, Kenichi (2006). O novo palco da economia global: desafios e possibilidades em um mundo sem fronteiras. Porto Alegre: Bookman.

SHAIKH, Anwar (1999). Explaining the Global Economic Crisis. New School University.

Recebido em: 01 de abril de 2010

Primeira resposta em: 29 de junho de 2010

Aceite em: 29 de junho de 2010 